Polymer Journal Vol. 1, No. 6, pp 632-638 (1970)

\title{
Volume Retardation of Polystyrene
}

\author{
Shiro Hozumi, Takashi Wakabayashi, and Kanji Sugihara \\ Wireless Research Laboratory, Matsushita Electric Industrial Co. Ltd. \\ Kadoma, Osaka, Japan.
}

(Received April 27, 1970)

\begin{abstract}
Isothermal volume retardation and shear-creep compliance are measured over a wide temperature range including the glass-transition region, the upper limit $T_{\mathrm{g}}{ }^{+}$ to the lower limit $T_{\mathrm{g}^{-}}$. . The equilibrium volume $V_{2}$ at the temperature below $T_{\mathrm{g}^{+}}{ }^{+}$is estimated from amount of vertical shift necessary for composing isotherms plotted in $V$ vs. $\log t$ into a master curve ( $V$, volume of the polymer; $t$, time). In the vicinity of $\mathrm{Tg}^{+}$, the temperature dependence of $V_{2}$ estimated as above agrees with that in the rubbery state. In the temperature range below $T_{\mathrm{g}}{ }^{-}$, however, the dependence differs from it. It is shown that horizontal shift factors of the volume retardation obtained in $T_{\mathrm{g}}{ }^{+}$ to $T_{\mathrm{g}}{ }^{-}$show a temperature dependence described fairly well by the WLF equation. The equation fits data on shear-creep compliance measured in the rubbery state. It is indicated that the rate of the volume retardation is represented as $\theta(T) \cdot \chi\left(V-V_{2}\right)$ where $\chi$ and $\theta$ are functions of temperature and $V-V_{2}$, respectively.

Anomalous isotherms which have a maximum, were studied experimentally. This phenomenon is qualitatively explained by an assumption of a wide distribution of retardation times. A position of the maximum is also interpreted in terms of a retardation time.
\end{abstract}

KEY WORDS Polystyrene/Volume Retardation/Equilibrium Volume/ Shift Factor/WLF Equation/Anomalous Isotherm/

The volume of a glassy substance undergoes an isothermal contraction or dilation accompanied by a retardation. This characteristic phenomenon, especially for organic polymers, has been studied extensively by numbers of investigators. $^{2-9}$ Much progress has been made in explaining the phenomenon. However, there are still problems to be studied; for example, distribution of retardation times, relation of free volume to the distribution of retardation times, and equilibrium volume at a temperature far below glass transition temperature. ${ }^{9,14}$

In the present paper, ${ }^{1}$ we report data on contraction isotherms and shear-creep compliances of polystyrene which were measured as a function of temperature, including the glass transition point of the polymer. The time-temperature relation on the volume retardation was studied and then compared with that on the shear-creep compliance. Temperature dependence of the equilibrium volume of the polymer was also studied in a temperature range below the glasstransition point. It is shown that time-temperature reducibility ${ }^{2}$ may be assumed for the volume retardation in the tempeaature range from the glass-transition point to 60 degrees below it. In the glass-transition region, equilibrium volume is still located on the extrapolation from that in the rubbery state. Temperature dependence of horizontal shift factors for superposition of the isotherms is fairly well explained in terms of the WLF equation. ${ }^{10}$ The equation was adapted to fit the data on shear-creep compliance measured in the rubbery state. Both temperature dependences of equilibrium volume and horizontal shift factor varied at around a temperature corresponding to the lower limit of the glass-transition region. The basis for our time-temperature reducibility on the volume retardation was clarified experimentally. Furthermore, anomalous isotherms* were studied for which the volume of the polymer goes through a maximum with time toward normal value. We believe that those isotherms may be an indication of some features which are rem-

* Such isotherms have been reported by Kovacs. ${ }^{2}$ Systematic analysis, however, has not been attempted as yet. 
iniscent of wide distribution of the retardation times.

\section{EXPERIMENTAL DETAILS AND RESULTS}

\section{Specimens}

Specimens were prepared by heating pelletized polystyrene at $150^{\circ} \mathrm{C}$ for one hour in vacuum and then molding it into a small rod at about $200^{\circ} \mathrm{C}$ in vacuum. Mitsubishi Dialex HF-66 was used as the starting material, the molecular weight of which is in the order of $5 \times 10^{4}$ to $10^{5}$. Thermal expansion of the polymer was measured while temperature was being decreased at a rate of about 1 degree per minute. The glass transition region was determined by this dilatometry ${ }^{11}$; the upper limit of that $T_{\mathrm{g}}{ }^{+}$is about $97^{\circ} \mathrm{C}$ and the lower limit $T_{\mathrm{g}}{ }^{-}$is about $73^{\circ} \mathrm{C}$. These results are presented in Figure 1.

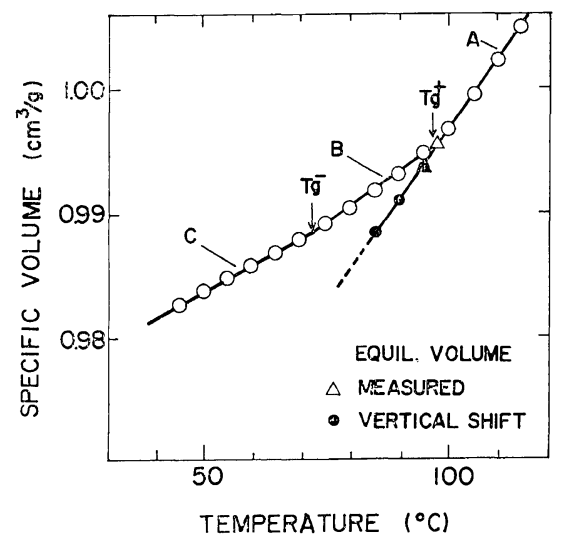

Figure 1. Thermal expansion and equilibrium valume of polystyrene. Open circles present the thermal expansion measured. The upper limit of the glass-transition region $T_{g^{+}} ; 97^{\circ} \mathrm{C}$. The lower limit of that $T_{g^{-}} ; 73^{\circ} \mathrm{C}$. These are determined from the intersections between lines $\mathrm{A}, \mathrm{B}$, and $\mathrm{C}$, as described in reference 11. Equilibrium volumes estimated from amounts of vertical shifts are normalized with respect to the value at $97.5^{\circ} \mathrm{C}$.

\section{Retardative Volume Change}

A mercury-dilatometer which consists of a bulb capacity of $10 \mathrm{~cm}^{3}$ and capillary diameter of $0.06 \mathrm{~cm}$ was used for measurements of volume change. Throughout measurements of the isotherm, the specimen was equilibrated at a temperature $T_{1}, 115^{\circ} \mathrm{C}$, in an oil bath before

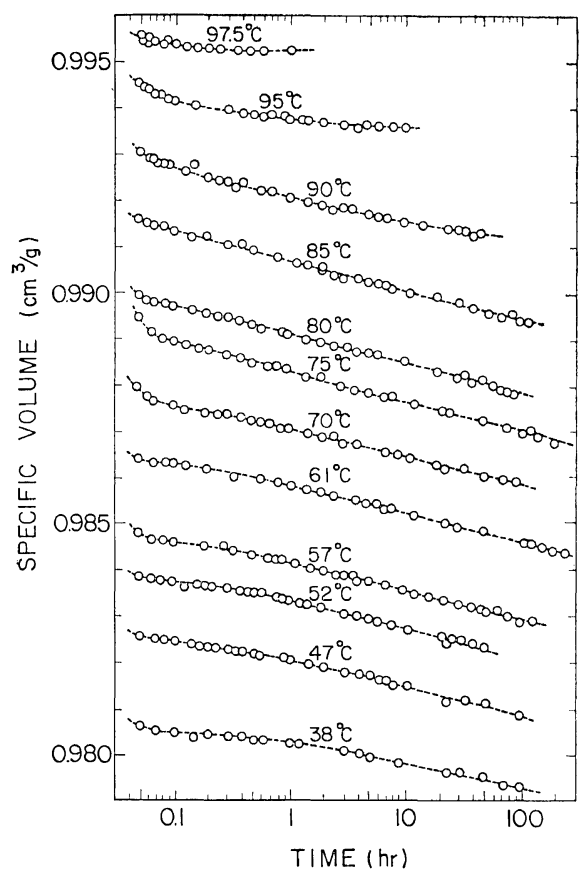

Figure 2. Isotherms of volume retardation for polystyrene obtained after quenching from $115^{\circ} \mathrm{C}$ to various temperatures. The temperatures are shown alongside isotherms.

each quenching. After that the dilatometer was transfered immediately from the bath to another bath maintained at a temperature $T_{2}$. Results are shown in Figure 2. Small scattering of the data in Figure 2 is due mainly to a small fluctuation in temperature caused from switching of the heater and/or change of room temperature.

The contraction isotherms were measured at twelve temperature points ranging from $97.5^{\circ} \mathrm{C}$ to $38^{\circ} \mathrm{C}$. Among these, the isotherms at 97.5 and $95^{\circ} \mathrm{C}$ alone reached the respective equilibrium values during the observation times.

When the specimen before reaching the equilibrium at $T_{2}$ was heated to $T_{3}$, which is lower than $T_{\mathrm{g}}{ }^{+}$, and allowed to make a retardation at $T_{3}$, its volume goes through a maximum toward contraction. $^{2}$ The isotherms obtained under such experimental conditions will be called hereafter "Anomalous isotherms". Three different conditions distinctive in their character were set up: (1) $115^{\circ} \mathrm{C} \rightarrow 80^{\circ} \mathrm{C} \rightarrow 88^{\circ} \mathrm{C}$ where $T_{2}$ and $T_{3}$ are higher than $T_{\mathrm{g}}{ }^{-}$. (2) $115^{\circ} \mathrm{C} \rightarrow 61^{\circ} \mathrm{C} \rightarrow$ $75^{\circ} \mathrm{C}$ where only $T_{3}$ is higher than $T_{\mathrm{g}}{ }^{-}$. (3) 


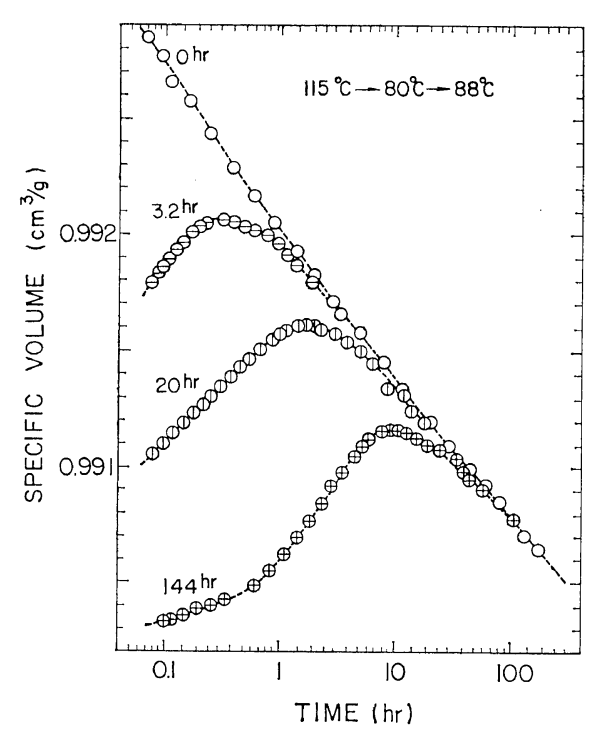

Figure 3. Anomalous volume retardation for polystyrene at $88^{\circ} \mathrm{C}$. Each of these isotherms is obtained under a quenching condition; the polymer has been maintained at $80^{\circ} \mathrm{C}$ during time $z$ after being quenched from $115^{\circ} \mathrm{C}$ to that temperature and then heated up to $88^{\circ} \mathrm{C}$. Each $z$ is shown alongside the isotherm.

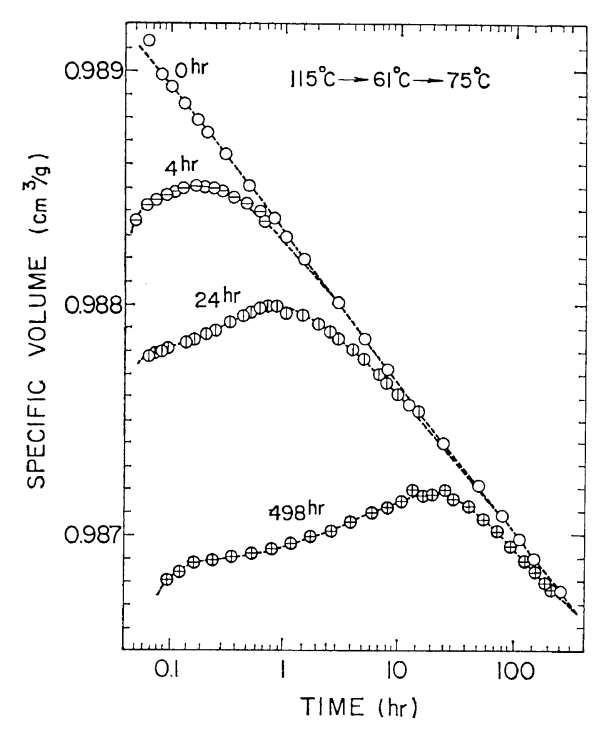

Figure 4. Anomalous volume retardation for polystyrene at $75^{\circ} \mathrm{C}$. Each of these isotherms is obtained under a similar quenching condition to that for the isotherms shown in Figure 3 varied in temperature combination; $115^{\circ} \mathrm{C} \rightarrow 61^{\circ} \mathrm{C} \rightarrow 75^{\circ} \mathrm{C}$.

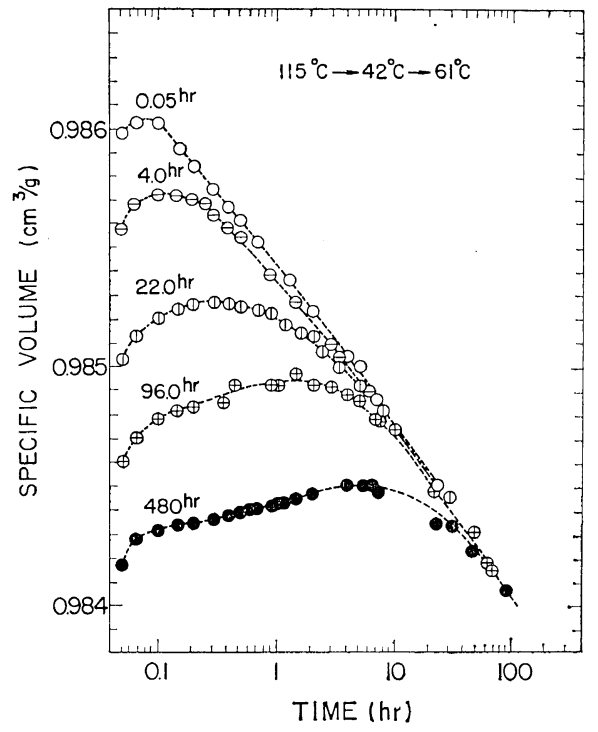

Figure 5. Anomalous volume retardation for polystyrene at $61^{\circ} \mathrm{C}$. Each of these isotherms is obtained under a similar quenching condition to that for the isotherms shown in Figure 3 varied in temperature combination; $115^{\circ} \mathrm{C} \rightarrow 42^{\circ} \mathrm{C} \rightarrow 61^{\circ} \mathrm{C}$.

$115^{\circ} \mathrm{C} \rightarrow 42^{\circ} \mathrm{C} \rightarrow 61^{\circ} \mathrm{C}$ where both $T_{2}$ and $T_{3}$ are lower than $\mathrm{T}_{\mathrm{g}}{ }^{-}$. Under these three conditions, a series of experiments was performed, in which the periods $z$ for the retardation at $T_{2}$ were varied. The results are shown in Figures 3, 4, and 5 .

\section{Shear-Creep Compliance}

Torsional creep tests were made with an arrangement almost similar to that described by Iwayanagi. $^{12}$ A differential transformer was used for detecting the torsion angle precisely and change in the angle was automatically recorded. The specimen was immersed in a silicone oil within a bath with electric heaters and a coiled tube for cooling water. Before each measurement at a temperature below $120^{\circ} \mathrm{C}$, the specimen was annealed at $120^{\circ} \mathrm{C}$. After that the temperature of the specimen was cooled. Throughout all measurements, a rod-shaped specimen $0.6 \mathrm{~cm}$ in diameter and $4 \mathrm{~cm}$ in effective length was used for the measurements at temperatures below $120^{\circ} \mathrm{C}$. In the temperature range above $120^{\circ} \mathrm{C}$, torsion force necessary for measurement is so small that it becomes difficult to apply the differential transformer to detect the torsion angle. In order to avoid this 


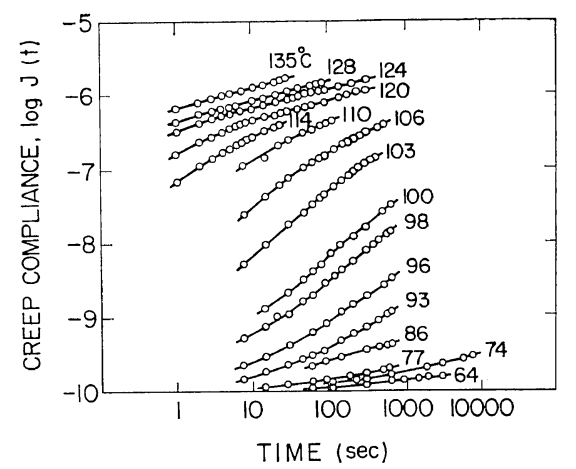

Figure 6. Shear creep compliance $\left(\mathrm{cm}^{2} / \mathrm{dyn}\right)$ of polystyrene against logarithmic time. Specimen is brought to each temperature after being annealed at $120^{\circ} \mathrm{C}$. Cooling rate for passing glass transition region is kept at $2 \mathrm{deg} / \mathrm{min}$.

difficulty, a rod-shaped specimen $1.0 \mathrm{~cm}$ in diameter and $2 \mathrm{~cm}$ in effective length was used for the measurements in this temperature range. It was certified that data obtained from two of the specimens were in agreement with each other at medium temperatures. The results are presented in Figure 6.

\section{DISCUSSION}

Superposition of Contraction Isotherms and Equilibrium Volume

According to Kovacs, ${ }^{2}$ when the isotherms represented as $\left(V-V_{2}\right) / T_{2}$ are taken against $\log t$, the resulting curves found over the temperature range from $T_{\mathrm{g}}$ to about ten degrees below $T_{\mathrm{g}}$ can be superposed as a single master curve by horizontal shifts of these curves, where $V$ is an instantaneous specific volume, $V_{2}$ is the equilibrium volume at $T_{2}, t$ is observation time and $T_{\mathrm{g}}$ is the glass-transition temperature somewhat lower than $T_{\mathrm{g}}{ }^{+}$. Furthermore Kovacs ${ }^{2}$ has shown that the temperature dependence of the respective amounts of horizontal shift, called horizontal shift factors, would be approximately represented in terms of the WLF equation. ${ }^{10}$

The situation mentioned above is applicable to the isotherms presented in Figure 2. If these isotherms are composed into a single curve by horizontal and vertical shifts, the amount of the vertical shift may provide information on the equilibrium volumes of the isotherms. Fol-

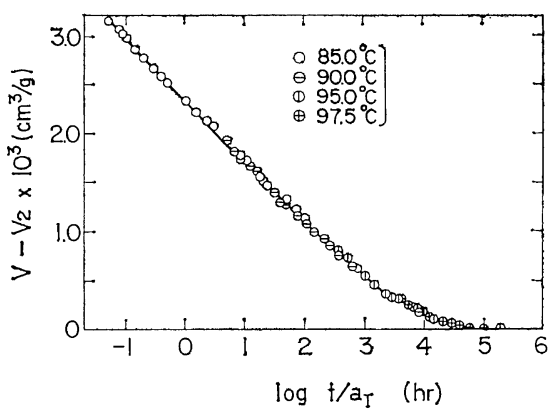

Figure 7. Master curve for isotherms of volume retardation in the vicinity of $T_{\mathrm{g}}{ }^{+}$reduced to $85^{\circ} \mathrm{C}$.

lowing this procedure, we obtained a master curve resulting in a temperature range of $97.5^{\circ} \mathrm{C}$ to $85^{\circ} \mathrm{C}$, and this master curve is shown in Figure 7. The relative values of $V_{2}$ estimated from the vertical shifts are presented in Figure 1 , where the values of $V_{2}$ are normalized with respect to the value measured at $97.5^{\circ} \mathrm{C}$. In Figure 1 another $V_{2}$ measured at $95^{\circ} \mathrm{C}$ is also plotted in comparison with the estimated value. The estimated value agrees with the measured value, and all of the estimated values lie on the line extrapolated from the equilibrium volumes in the rubbery state. This fact reinforces the prediction deduced from the free volume theory of viscoelasticity. ${ }^{13,14}$

Because the isotherms show almost parallel lienes with each other, it is impossible to determine the shift factors as unitary values as to the isotherms obtained at temperatures from about $80^{\circ} \mathrm{C}$ to about $70^{\circ} \mathrm{C}$. However, if an

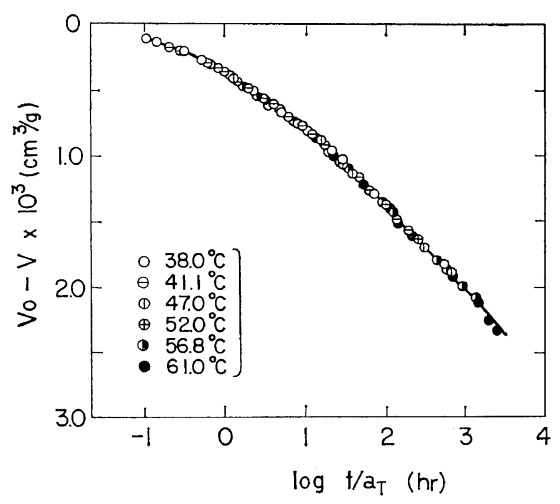

Figure 8. Master curve for isotherms of volume retardation in glassy state reduced to $38^{\circ} \mathrm{C}$. 


\section{S. Hozumi, T. Wakabayashi and K. Sugihara}

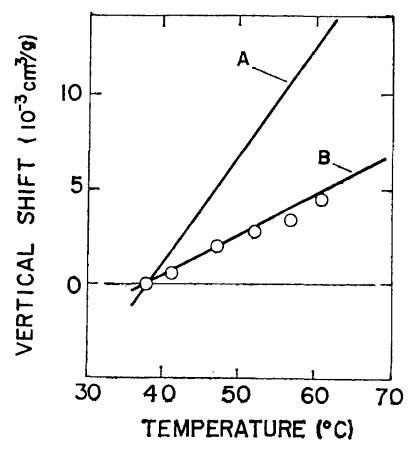

Figure 9. Relative amounts of vertical shift in glassy state against temperature. Solid lines A and $\mathbf{B}$ show the slopes of thermal expansion in the rubbery state and the glassy state taken from the curve in Figure 1.

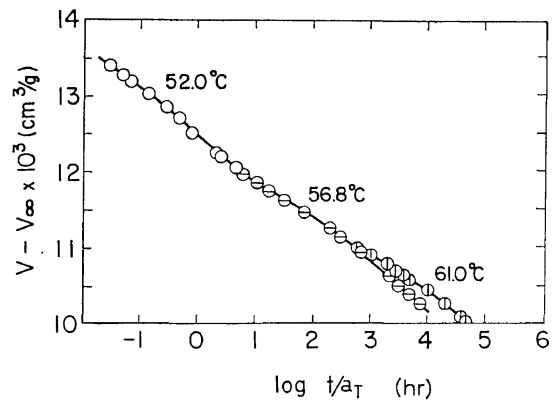

Figure 10. Superposition of isotherms in glassy state resulting from an assumption that equilibrium volume would be still located on the straight extrapolation from that in the rubbery state.

isotherm below $70^{\circ} \mathrm{C}$ at small $t$ deviates from a line, a determination of the vertical and the horizontal shift factors become possible. The master curve in the temperature region below $61^{\circ} \mathrm{C}$ is presented in Figure 8. The relative amounts of the vertical shift are shown in Figure 9, in comparison with the slopes of thermal expansions in the glassy state and the rubbery state taken from Figure 1. The behavior of $V_{2}$ at these temperatures is different from that at higher temperatures and the temperature dependence of $V_{2}$ is almost equal to that of the glassy-polymer volume. If one assumes that the equilibrium volumes still lie on the extrapolation from the rubbery state even at these low temperatures, the isotherms at these temperatures cannot be composed into a single curve, as shown in Figure 10.

\section{Time-Temperature Reducibility}

As is well known, creep compliances as a function of logarithmic time are composed into a master curve by horizontal and vertical shift. ${ }^{15}$ This procedure is applied to the present data, and the resulting master curve is presented in Figure 11. The horizontal shift factors, $\log a_{\mathrm{T}^{\prime}}$ are shown in Figure 12. The solid curve shows the WLF equation presented as a universal formula ${ }^{10,16}$ in the following

$$
\log a_{\mathrm{T}}=\frac{-8.86\left(T-T_{\mathrm{s}}\right)}{101.6+\left(T-T_{\mathrm{s}}\right)},
$$

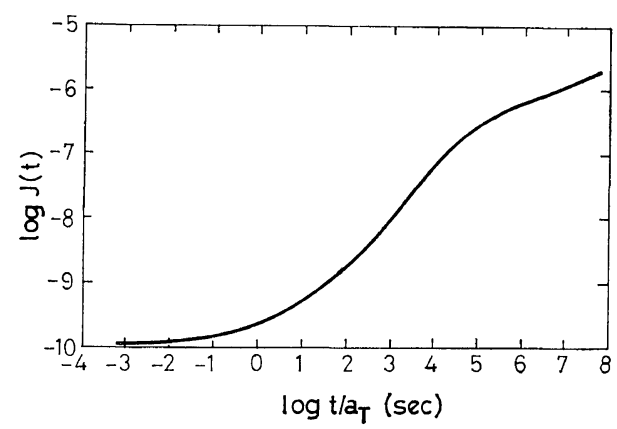

Figure 11. Master curve for shear creep compliance $\left(\mathrm{cm}^{2} / \mathrm{dyn}\right)$ of polystyrene reduced to $100^{\circ} \mathrm{C}$.

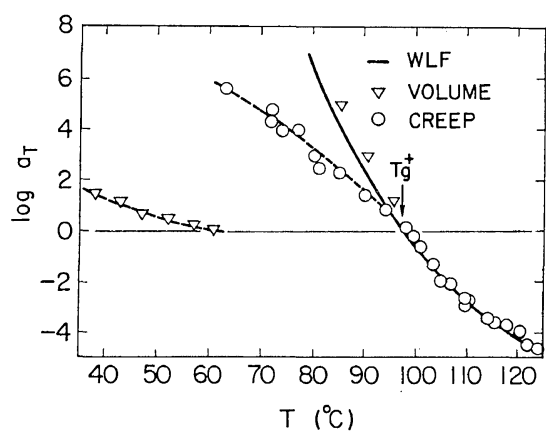

Figure 12. Temperature dependences of horizontal shift factors used in plotting the master curves shown in Figures 7, 8, and 11. Shift factors of volume retardation at high temperatures are normalized with respect to the value at $97.5^{\circ} \mathrm{C}$. Those at low temperatures are normalized with respect to the value at $61^{\circ} \mathrm{C}$. Solid curve presents the universal WLF equation ${ }^{10,16}$ with $T_{s}=139^{\circ} \mathrm{C}$, which is adapted to fit the data on shear-creep compliance at temperatures above $T_{g}{ }^{+}$. 
where $T_{\mathrm{s}}$ is $139^{\circ} \mathrm{C}$. The value of $T_{\mathrm{s}}$ is determined so that the equation may describe the data of the horizontal shift factors obtained at temperatures above $\mathrm{T}_{\mathrm{g}}{ }^{+}$. As is well established by Hideshima, ${ }^{17}$ the temperature dependence of the horizontal shift factors is described by the WLF equation at temperatures higher than $T_{\mathrm{g}}{ }^{+}$; however, the dependence deviates suddenly from the equation below $T_{\mathrm{g}}{ }^{+}$on account of the glass transition. The horizontal shift factors of the volume retardation obtained in the previous section are compared with those of the shear creep compliances, as shown in Figure 12. The temperature dependence of the shift factors of the volume retardation in the vicinity of $T_{\mathrm{g}}{ }^{+}$ is described fairly well by the WLF equation which fits the data on the shear compliances obtained at temperatures higher than $T_{\mathrm{g}}{ }^{+}$. Such dependence is very distinct from the behavior at temperatures below $T_{\mathrm{g}}{ }^{-}$.

Adam $^{4}$ proposed a theoretical equation manifesting the isothermal volume retardation. His equation can be written as,

$$
\frac{\mathrm{d} V}{\mathrm{~d} t}=\theta\left(T_{2}\right) \cdot \chi\left(V-V_{2}\right),
$$

where $\theta\left(T_{2}\right)$ is a function of $T_{2}$ only, and $\chi$ is a function of $\left(V-V_{2}\right)$. Considering that $(\mathrm{d} V /$ $\mathrm{d} \ln t)$ can be reformed as $(\mathrm{d} V / \mathrm{d} t) t$, eq 2 satisfies the condition for the time-temperature reducibility. The horizontal shift factor corre-

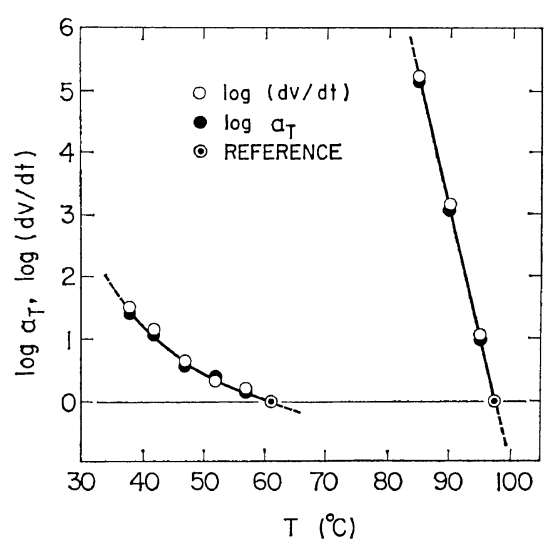

Figure 13. Temperature dependences of horizontal shift factor and relative value of rate of volume contraction $\mathrm{d} V / \mathrm{d} t$ determined at a constant value of $V-V_{2}$. sponds to $\theta\left(T_{2}\right) / \theta\left(T_{2 r}\right)$ where $T_{2 r}$ is a reference temperature. The relative values of $\mathrm{d} V / \mathrm{d} t$ are graphically determined on the isotherms where the values of $V-V_{2}$ are constant. In this procedure, the values of $V_{2}$ obtained in the previous section are used. The results are presented in Figure 13 and are compared with data from shift factors already shown in Figure 12. Both of the these results agree well throughout the temperature range investigated. The timetemperature reducibility on the volume retardation may be understood from the formalism of eq 2.

\section{Anomalous Isotherms}

A systematic study of the anomalous isotherms is not formed in literature. It has been suggested that the anomalous isotherm is one of several phenomena which may reveal information on distribution of retardation times. ${ }^{1,14}$ The mechanism of the occurrence of the anomalous isotherms is qualitatively explained on the basis of the assumption for the distribution of the retardation times. Let us assume that an apparent volume retardation of a polymer comprises many retardation elements which are characterized by the retardation times. When the polymer is quenched from $T_{1}$ to $T_{2}$ and is made to retard at $T_{2}$ during period $z$, the retardation elements having shorter retardation times than $z$ make the transitions from the states at $T_{1}$ to those at $T_{2}$ while the retardation elements having longer retardation times than $z$ remain in the states at $T_{1}$. In this situation, if the polymer is heated from $T_{2}$ to $T_{3}$, the retardation elements which have reached the states at $T_{2}$ start to make transitions from the state at $T_{2}$ to $T_{3}$ so that the shorter the retardation time, the faster the start will be. And, then, the retardation elements remaining in the state at $T_{1}$ start to make transitions from the state at $T_{1}$ to $T_{3}$. On the basis of this explanation, it is expected that the time $t_{\max }$ at which the anomalous isotherm shows the maximum will closely relate to the time $z$ throughout the anomalous isotherms obtained in each combination of $T_{1}, T_{2}$, and $T_{3}$. Figure 14 shows the correlation between $t_{\max }$ and $z$, obtained from Figures 3, 4, and 5 . The apparent activation energies of retardation are obtained from Figure 14, since the ratio of 


\section{S. Hozumi, T. Wakabayashi and K. Sugihara}

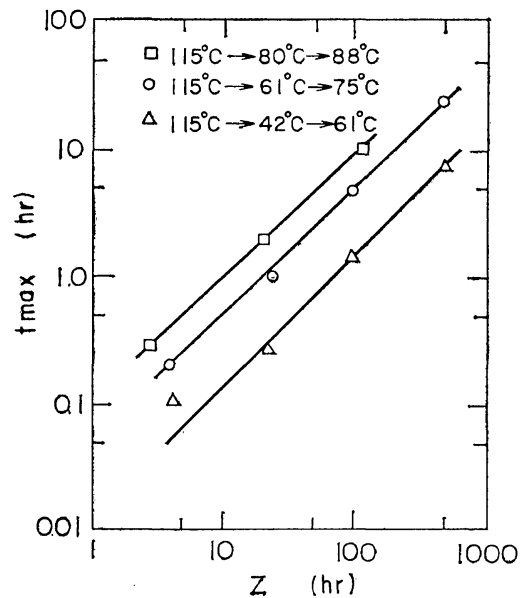

Figure 14. Relation between $t_{\max }$ and $z: t_{\max }$, time corresponding to maximum position on an anomalous volume retardation; $z$, time during which polymer having been maintained at a temperature of 80,61 and $42^{\circ} \mathrm{C}$ before being heated up to a final temperature.

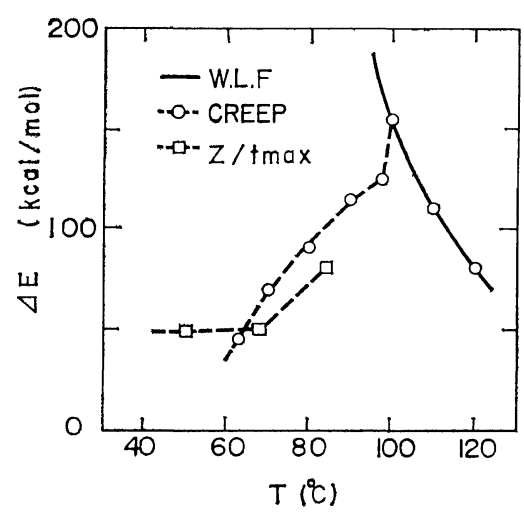

Figure 15. Apparent activation energies obtained from temperature dependence of shear-creep compliance presented in Figure 12 and that of value $z / t_{\max }$ taken from the results shown in Figure 14.

$z$ to $t_{\max }$ expresses the ratio of the averaged effective retardation time at $T_{2}$ to that at $T_{3}$. These values are about $80 \mathrm{kcal} / \mathrm{mol}$ above $T_{\mathrm{g}}{ }^{-}$ and about $50 \mathrm{kcal} / \mathrm{mol}$ below $T_{\mathrm{g}}{ }^{-}$. These activation energies would reflect the temperature dependence of the effective compliances in the non equilibrium states, and these values may be compared with the apparent activation energies of the shear creep compliances obtainable from data in Figure 12. This comparison is shown in Figure 15. The values of the apparant acti- vation energies obtained from the volume retardations and that from the shear compliances are in fair agreement with each other for the temperature range studied.

Acknowledgement. The authors wish to express their sincere appreciation to Prof. Y. Wada for first drawing their attention to the volume retardation phenomena and for valuable discussions during this work. They also wish to thank the late Prof. N. Hirai for his encouragement during the early stages of this work. They thank Dr. S. Kisaka for his encouragement and for permission to publish the paper, and are grateful to Prof. D.H. Chung for reading and criticizing the manuscript. They are especially indebted to $\mathrm{Mr}$. H. Isogai for his measurements on the torsional-creep compliances.

\section{REFERENCES}

1. A part of this work was presented in the following short note. S. Hozumi, T. Wakabayashi, H. Watanabe, and K. Sugihara, Repts. Progr. Polymer Phys. Japan, 7, 101 (1964); S. Hozumi, T. Wakabayashi, and K. Sugihara, ibid., 7, 105 (1964).

2. A. J. Kovacs, J. Polym. Sci., 30, 131, (1958).

3. N. Hirai and H. Erying, J. Polym. Sci., 37, 51(1959).

4. G. Adam, Kolloid Z.u.Z. Polym., 180, 11 (1962).

5. A. J. Kovacs, Compt. rend., 250, 109 (1960).

6. T. Hideshima and K. Okano, Repts. Progr. Polym. Phys. Japan, 4, 51 (1961).

7. K. Okano, Repts. Progr. Polym. Phys., 6, 45 (1963); 7, 89, (1964).

8. F. Bueche, J. Chem. Phys., 36, 2940 (1962).

9. G. Goldbach and G. Rehage, Rheol. Acta, 6, 30 (1967).

10. M. L. Williams, R. E .Landel, and J. D. Ferry, J. Amer Chem. Soc., 77, 3701 (1955).

11. Y. Wada, H. Hirose, T. Asano, and S. Fukutomi, J. Phys. Soc. Japan, 14, 1004 (1959).

12. S. Iwayanagi, J. Sci. Res. Inst, 49, 4 (1955).

13. N. Saito, et al., "Solid State Physics" Vol. 14, F. Seitz and D. Turnbull, Ed., Academic Press, N.Y., 1962, p 343.

14. A. J. Kovacs, Rheol. Acta, 5, 262 (1966).

15. J. D. Ferry, "Viscoelastic Properties of Polymers," Johns Wiley \& Sons. Inc. N.Y. and London, 1961, p 201.

16. J. D. Ferry, ibid., 1961, p 228.

17. T. Hideshima, Repts. Progr. Polym. Phys. Japan, 5, 103 (1962) 